\title{
CD36 inhibition prevents lipid accumulation and contractile dysfunction in rat cardiomyocytes
}

Citation for published version (APA):

Angin, Y., Steinbusch, L. K. M., Simons, P. J., Greulich, S., Hoebers, N. T. H., Douma, K., van Zandvoort, M. A. M. J., Coumans, W. A., Wijnen, W., Diamant, M., Ouwens, D. M., Glatz, J. F. C., \& Luiken, J. J. F. P. (2012). CD36 inhibition prevents lipid accumulation and contractile dysfunction in rat cardiomyocytes. Biochemical Journal, 448, 43-53. https://doi.org/10.1042/BJ20120060

Document status and date:

Published: 15/11/2012

DOI:

10.1042/BJ20120060

Document Version:

Publisher's PDF, also known as Version of record

Document license:

Taverne

Please check the document version of this publication:

- A submitted manuscript is the version of the article upon submission and before peer-review. There can be important differences between the submitted version and the official published version of record.

People interested in the research are advised to contact the author for the final version of the publication, or visit the DOI to the publisher's website.

- The final author version and the galley proof are versions of the publication after peer review.

- The final published version features the final layout of the paper including the volume, issue and page numbers.

Link to publication

\footnotetext{
General rights rights.

- You may freely distribute the URL identifying the publication in the public portal. please follow below link for the End User Agreement:

www.umlib.nl/taverne-license

Take down policy

If you believe that this document breaches copyright please contact us at:

repository@maastrichtuniversity.nl

providing details and we will investigate your claim.
}

Copyright and moral rights for the publications made accessible in the public portal are retained by the authors and/or other copyright owners and it is a condition of accessing publications that users recognise and abide by the legal requirements associated with these

- Users may download and print one copy of any publication from the public portal for the purpose of private study or research.

- You may not further distribute the material or use it for any profit-making activity or commercial gain

If the publication is distributed under the terms of Article $25 \mathrm{fa}$ of the Dutch Copyright Act, indicated by the "Taverne" license above, 


\title{
CD36 inhibition prevents lipid accumulation and contractile dysfunction in rat cardiomyocytes
}

\author{
Yeliz ANGIN*1,2, Laura K. M. STEINBUSCH ${ }^{\star 1}$, Peter J. SIMONS $\dagger$, Sabrina GREULICH $\ddagger$, Nicole T. H. HOEBERS*, Kim DOUMA*, \\ Marc A. M. J. van ZANDVOORT*, Will A. COUMANS* ${ }^{\star}$, Wino WIJNEN* ${ }^{\star}$, Michaela DIAMANT§, D. Margriet OUWENS $\ddagger$, \\ Jan F. C. GLATZ* and Joost J. F. P. LUIKEN* \\ *CARIM, Maastricht University, Universiteitssingel 50, P.0. Box 616, 6200 MD Maastricht, The Netherlands, † $†$ Bioceros BV, Yalelaan 46, 3584 CM Utrecht, The Netherlands, \\ ¥German Diabetes Center, Auf'm Hennekamp 65, 40225 Düsseldorf, Germany, and §̧Diabetes Center, VUmc, Postbus 7057, 1007 MB Amsterdam, The Netherlands
}

\begin{abstract}
An increased cardiac fatty acid supply and increased sarcolemmal presence of the long-chain fatty acid transporter CD36 are associated with and contribute to impaired cardiac insulin sensitivity and function. In the present study we aimed at preventing the development of insulin resistance and contractile dysfunction in cardiomyocytes by blocking CD36mediated palmitate uptake. Insulin resistance and contractile dysfunction were induced in primary cardiomyocytes by $48 \mathrm{~h}$ incubation in media containing either $100 \mathrm{nM}$ insulin (high insulin; HI) or $200 \mu \mathrm{M}$ palmitate (high palmitate; HP). Under both culture conditions, insulin-stimulated glucose uptake and Akt phosphorylation were abrogated or markedly reduced. Furthermore, cardiomyocytes cultured in each medium displayed elevated sarcolemmal CD36 content, increased basal palmitate uptake, lipid accumulation and decreased sarcomere shortening.
\end{abstract}

Immunochemical CD36 inhibition enhanced basal glucose uptake and prevented elevated basal palmitate uptake, triacylglycerol accumulation and contractile dysfunction in cardiomyocytes cultured in either medium. Additionally, CD36 inhibition prevented loss of insulin signalling in cells cultured in HP, but not in HI medium. In conclusion, CD36 inhibition prevents lipid accumulation and lipid-induced contractile dysfunction in cardiomyocytes, but probably independently of effects on insulin signalling. Nonetheless, pharmacological CD36 inhibition may be considered as a treatment strategy to counteract impaired functioning of the lipid-loaded heart.

Key words: cardiac metabolism, CD36, diabetes, insulin resistance, lipid accumulation.

\section{INTRODUCTION}

Increased cardiac lipid content has been associated with pathophysiological conditions, such as cardiac insulin resistance and contractile dysfunction, which may lead to the development of diabetic cardiomyopathy [1-3]. Cardiac lipid accumulation occurs as a result of elevated LCFA (long-chain fatty acid) supply [4] and/or increased uptake of LCFAs [5-7]. Excessive entry of LCFAs into cardiomyocytes provides increased substrates for mitochondrial LCFA oxidation. When the flux of incoming LCFAs exceeds the mitochondrial $\beta$-oxidation capacity, LCFAs will increasingly be stored as triacylglycerols and converted into bio-active metabolites such as diacylglycerols. Notably, there is a strong correlation between triacylglycerol storage and insulin resistance [8,9]. Moreover, diacylglycerols have been regarded to be causal to the development of insulin resistance through activation of PKC (protein kinase $\mathrm{C}$ )-mediated serine/threonine phosphorylation of the insulin receptor substrate, thereby impairing downstream insulin signalling [10].

Glucose and LCFAs are the major energy substrates for the heart. Cardiac substrate uptake is dependent on plasma glucose and LCFA concentrations, as well as the sarcolemmal presence of glucose and LCFA transporters [7,11]. The main GLUT (glucose transporter) in the heart is GLUT4, whereas LCFA uptake is largely mediated by CD36 [12]. Also other LCFA transporters have been found to be present in the heart, such as members of the family of FATPs (fatty acid transporter proteins), but these proteins have a minor role in bulk uptake of LCFAs into the heart [7]. Insulin is a major physiological stimulator of cardiac glucose and fatty acid uptake. Insulin-stimulated glucose uptake is due to GLUT4 translocation from intracellular compartments to the sarcolemma via a vesicle-mediated process [12-14]. A similar vesicle-mediated process is also responsible for CD36 translocation from intracellular compartments to the sarcolemma, which entirely accounts for insulin-stimulated LCFA uptake [12]. Accordingly, in cardiomyocytes from CD36-knockout mice, insulin-induced CD36 translocation is completely abolished [15].

The expression of CD36 in the heart is not changed in rodent models of insulin resistance. However, this transporter has been shown to permanently relocate from intracellular stores to the sarcolemma. This CD36 relocation will cause chronically elevated LCFA uptake into the heart, followed by myocellular lipid accumulation, and consequently insulin resistance $[7,16,17]$. Ultimately, permanent sarcolemmal CD36 relocation may lead to cardiac dysfunction [16]. Accordingly, ablation of CD36 has been shown to preserve cardiac function in Western diet-fed mice [18], and also in mice suffering from $\operatorname{PPAR} \alpha$ (peroxisome-proliferatoractivated receptor $\alpha$ ) overexpression-induced lipotoxicity [19]. Taken together, CD36 and its increased abundance at the sarcolemma play a key role in the development of high-fat dietinduced cardiac dysfunction.

CD36 is a multifactorial protein and has different functions in different cell types. Several endogenous CD36 ligands (LCFAs, thrombospondin-1 and oxidized low-density lipoproteins) with different binding regions on the extracellular domain of CD36 are known [20-22]. In addition, synthetic CD36-specific binding

Abbreviations used: AMPK, AMP-activated protein kinase; AS160, Akt substrate of 160 kDa; DTT, dithiothreitol; GLUT, glucose transporter; GSK3 $\beta$, glycogen synthase kinase $3 \beta$; HI, high insulin; HP, high palmitate; LCFA, long-chain fatty acid; mAb, monoclonal antibody; SSO, sulfo- $N$-succinimydyl oleate.

1 These authors contributed equally to this work.

2 To whom correspondence should be addressed (email y.angin@maastrichtuniversity.nl). 
molecules [SSO (sulfo- $N$-succinimydyl oleate), hexarelin and EP80317] and antibodies have been introduced [23,24]. Sulfo- $N$ succinimidyl esters of LCFAs have proven to block initial LCFA uptake into heart and muscle [25]. However, they are not useful in long-term experiments because of their chemical instability [24]. In the search for other CD36 ligands that interfere with the fatty acid transport function of CD36, we tested whether hexarelin, EP80317 and anti-CD36 mAbs (monoclonal antibodies) would inhibit short-term LCFA uptake into cardiomyocytes prior to testing their protective potential against the detrimental effects of cardiomyocytic lipid overload.

To test the putative preventive effect of CD36 ligands on cardiomyocyte lipid accumulation, insulin resistance and contractile dysfunction, we first needed to establish suitable culture conditions in which cardiomyocytes develop excessive lipid storage and loss of insulin signalling and contractile function. For this, we chronically exposed rat primary cardiomyocytes to two different media. One medium contained a high concentration of insulin (HI), because insulin is known to induce CD36 translocation to the sarcolemma and thereby increase LCFA uptake and lipid accumulation. It is also known that chronic insulin treatment induces loss of insulin signalling in cardiomyocytes [26]. A second medium contained a high concentration of palmitate (HP), which is known to reduce contractile function [27]. As a result, cardiomyocytes were cultured in a $\mathrm{HI}$ or a HP medium with/without a CD36-blocking compound. Then, we evaluated the cultured cardiomyocytes on the presence of surface CD36, glucose and LCFA uptake, insulin signalling, myocellular lipid content and contractile function. We describe in the present paper that inhibition of CD36-mediated LCFA uptake by a CD36-blocking compound prevents lipid accumulation and loss of sarcomere shortening in these cultured cardiomyocytes.

\section{MATERIALS AND METHODS}

\section{Materials}

$\left[{ }^{14} \mathrm{C}\right]$ Palmitic acid and $\left[{ }^{3} \mathrm{H}\right]$ deoxyglucose were obtained from $\mathrm{GE}$ Healthcare. $\left[{ }^{3} \mathrm{H}\right]$ Chloroquine was from Moravek Biochemicals. Laminin and insulin were purchased from Sigma. BSA (fraction V), dependent on the application, was derived from MP Biomedicals (for cell isolation and incubation purposes) or from Sigma (other purposes). Collagenase type II was from Worthington. SSO was synthesized in our laboratory [28] and EP80317 was from Bio-Connect (special production by Peptides International). Hexarelin was a gift from Professor J. Heemskerk (CARIM, Maastricht, The Netherlands). The anti-CD36 mAb clone 63 (anti-CD36-cl63; also known as clone CRF D2717) was from BD Biosciences, and was provided by Bioceros BV. The antiCD36 mAb clone 10E10 (anti-CD36-cl10E10) was produced by Bioceros BV.

\section{Experimental animals}

Male Lewis rats (200-250 g), were purchased from Charles River Laboratories and were used for cardiomyocyte isolation. All animals were fed ad libitum and kept under normal $12 \mathrm{~h} / 12 \mathrm{~h}$ dark-light cycles. All procedures were approved by the Experimental Animal Committee of Maastricht University, Maastricht, The Netherlands.

\section{Cardiomyocyte isolation and culturing}

Cardiomyocyte isolations were performed as described previously [29] with the only difference being the sterile conditions that were taken into account for subsequent culturing. After isolation of cardiomyocytes, 200000 cells/well were routinely seeded in laminin-coated six-well plates (9.6 $\mathrm{cm}^{2}$ ), unless specified otherwise. After $90 \mathrm{~min}$ adhesion in modified Krebs-Ringer medium [30] supplemented with $0.45 \% \mathrm{BSA}$, the adhesion medium was replaced with control medium [M199 supplemented with $5 \mathrm{mM}$ creatine monohydrate, $3.2 \mathrm{mM}$ carnitine hydrochloride, $3.1 \mathrm{mM}$ taurine, $100 \mathrm{units} / \mathrm{ml}$ penicillin and $10 \mathrm{mg} / \mathrm{ml}$ streptomycin and $20 \mu \mathrm{M}$ palmitate (palmitate/BSA, 0.3:1)], HI medium (control medium supplemented with $100 \mathrm{nM}$ insulin) or HP medium [control medium with an additional $200 \mu \mathrm{M}$ palmitate (palmitate/BSA, $3: 1)$ ]. Cells were cultured for $48 \mathrm{~h}$ and for measurements of shortterm insulin effects cardiomyocytes were washed with modified Krebs-Ringer solution supplemented with $0.45 \%$ BSA and $1 \mathrm{mM}$ $\mathrm{CaCl}_{2}$ (medium A) and left untreated for $30 \mathrm{~min}$ (explained in detail in the Results section).

\section{Measurement of substrate uptake}

We measured uptake of $\left[1-{ }^{14} \mathrm{C}\right]$ palmitate (in complex with BSA) and $\left[{ }^{3} \mathrm{H}\right]$ deoxyglucose into freshly isolated cardiomyocytes [30] as well as into cardiomyocytes in culture [13], as described previously. With respect to freshly isolated cardiomyocytes, cells were pre-incubated with anti-CD36-specific binding molecules $(500 \mu \mathrm{M}$ SSO, $100 \mu \mathrm{M}$ EP80317, $20 \mu \mathrm{M}$ hexarelin, $0.83 \mu \mathrm{g} / \mathrm{ml}$ anti-CD36-cl63 and $1.7 \mu \mathrm{g} / \mathrm{ml}$ anti-CD36-cl10E10) at $37^{\circ} \mathrm{C}$ while shaking for $20 \mathrm{~min}$, and subsequently incubated without/with oligomycin $(5 \mu \mathrm{M})$ for an additional $20 \mathrm{~min}$. Then, a mixture of $\left[{ }^{3} \mathrm{H}\right]$ glucose and $\left[{ }^{14} \mathrm{C}\right]$ palmitate was added for the last 5 min of incubation and radioactivity was measured in scintillation fluid (Opti-Fluor; PerkinElmer).

For cardiomyocytes that had been cultured for 2 days, a mixture of $\left[{ }^{3} \mathrm{H}\right]$ glucose and $\left[{ }^{14} \mathrm{C}\right]$ palmitate was added for $10 \mathrm{~min}$ directly following a $15 \mathrm{~min}$ incubation period with/without insulin $(100 \mathrm{nM})$. Then, cells were washed with Stop medium (modified Krebs-Ringer buffer with $1 \mathrm{mM} \mathrm{Ca}^{2+}$ and $0.2 \mathrm{mM}$ phloretin) on ice, lysed in sample buffer [ $40 \%$ glycerol, $0.25 \mathrm{M}$ Tris and $1 \mathrm{M}$ DTT (dithiothreitol)] and radioactivity was measured in scintillation fluid (Opti-Fluor; PerkinElmer).

\section{Detection of phosphorylation of enzymes within the insulin signalling network}

Following a 15 min treatment with/without insulin $(100 \mathrm{nM})$, cells were lysed in sample buffer $(40 \%$ glycerol, $0.25 \mathrm{M}$ Tris, $1 \mathrm{M}$ DTT and $1.5 \mathrm{mM}$ Bromophenol Blue) and used for protein detection by SDS/PAGE $(20 \mu \mathrm{g}$ of protein per lane), followed by Western blotting, as described previously [31]. Antibodies against phospho-Ser ${ }^{473}$-Akt, Akt, phospho-Ser ${ }^{9}-$ GSK3 $\beta$ (glycogen synthase kinase $3 \beta$ ) and GSK3 $\beta$ were purchased from Cell Signaling Technology, against phospho-Thr ${ }^{642}$ AS160 (Akt substrate of $160 \mathrm{kDa}$ ) was purchased from Upstate Biotechnology, against CD36 was purchased from GenTex, against GLUT4 and GAPDH (glyceraldehyde-3-phosphate dehydrogenase) was purchased from Abcam, and against caveolin 3 was purchased from BD Transduction Laboratories. The antiCD36 monoclonal antibody MO25 was a gift from Dr N.N. Tandon (Thrombosis Research Laboratory, Otsuka Maryland Medicinal Laboratories Rockville, MS, U.S.A.) and was used only for Western blotting. Western blot images were analysed with a molecular imager (ChemiDoc XRS, Bio-Rad Laboratories) and quantified with Quantity One ${ }^{\circledR}$ (Bio-Rad Laboratories). 


\section{Measurement of sarcomere shortening and $\mathrm{Ca}^{2}+$ fluxes}

For measurement of sarcomere shortening and $\mathrm{Ca}^{2+}$ fluxes, cells were cultured on 35-mm high dishes with an elastic surface from Ibidi. After 2 days of culture, cells were preloaded with fura 2/AM (fura 2 acetoxymethyl ester) (Merck Chemicals) for $25 \mathrm{~min}$ at room temperature $\left(24^{\circ} \mathrm{C}\right)$, washed twice with control M199 and then incubated for 20 min with M199. Subsequently, contractile function and $\mathrm{Ca}^{2+}$ transients were analysed in cells showing an intact rod-shaped morphology and sarcomere length $>1.6 \mu \mathrm{m}$ as described previously [32]. Before the start of measurement, cells were electrically pre-stimulated for $5 \mathrm{~min}$ with $1 \mathrm{~Hz}$ to reach a steady-state level for sarcomere shortening and fura 2 fluorescence. Then, cells were paced with bipolar pulses of $5 \mathrm{~ms}$ duration at $1 \mathrm{~Hz}$. The cytosolic $\mathrm{Ca}^{2+}$ concentration was monitored as a ratio of the fluorescence emission peaks at 340 and $380 \mathrm{~nm}$. Under each experimental condition, data files were recorded of ten consecutive beats for at least eight different cells. Sarcomere shortening and $\mathrm{Ca}^{2+}$ transients were measured with a fluorescence system from IonOptix and calculated using IonWizard (IonOptix).

\section{Myocellular triacylglycerol and diacylglycerol contents}

For measurement of intramyocellular lipid content, cardiomyocytes were cultured in $55 \mathrm{~cm}^{2}$ glass petridishes with a $1 \times 10^{6}$ cell density. Intramyocellular lipids were determined after 2 days of culturing as described previously [33]. Briefly, samples containing $400 \mu \mathrm{g}$ of protein were used for intracellular lipid extraction in methanol/chloroform, and an internal standard and water were added. Afterwards TLC was used to separate lipids. Bands were resolved with a hexane/diethylether/propanol (87:10:3) resolving solution. Triacylglycerol and diacylglycerol bands were detected with a molecular imager (ChemiDoc XRS, BioRad Laboratories) and analysed with Quantity One ${ }^{\circledR}$ (Bio-Rad Laboratories).

\section{Sarcolemmal presence of CD36}

Following a $15 \mathrm{~min}$ treatment with/without insulin $(100 \mathrm{nM})$, cells were incubated for $10 \mathrm{~min}$ with $2 \mu \mathrm{g} / \mathrm{ml}$ anti-CD36-cl63, which is known to cross-react with rat CD36, and FITC-labelled rabbitanti-mouse IgA secondary antibodies (1:500 dilution; Rockland). Cardiomyocytes were washed with adhesion medium and then the viable cardiomyocytes were imaged using the Leica SP5 imaging platform in two-photon mode (Leica Microsystems) with the emission filters optimized for FITC detection. Images were processed with ImageJ (NIH). Cardiomyocytes were kept at $37^{\circ} \mathrm{C}$ during incubation and imaging.

\section{Statistics}

Differences among the data obtained from five to eight experiments are presented as means \pm S.E.M. Statistical differences between groups of observations were evaluated by unpaired Student's $t$ test, one-way ANOVA or two-way ANOVA, depending on the groups compared. $P$ values equal to or less than 0.05 were considered as significant.

\section{RESULTS}

\section{Anti-CD36-cl63 treatment inhibits LCFA uptake in freshly isolated cardiomyocytes}

Our first aim was to select a CD36 ligand that would inhibit LCFA uptake into cardiomyocyte cultures. Therefore we tested the ability of hexarelin $(100 \mu \mathrm{M}), \operatorname{EP} 80317(20 \mu \mathrm{M})$ and two distinct anti-CD36 antibodies, i.e. anti-CD36-cl63 $(0.83 \mu \mathrm{g} / \mathrm{ml})$ and anti-CD36-cl10E10 $(1.7 \mu \mathrm{g} / \mathrm{ml})$, to block short-term LCFA uptake into cardiomyocytes under basal conditions, and found that only anti-CD36-cl63 was effective (Figure 1A). In addition, the specific CD36 inhibitor SSO modestly inhibited basal LCFA uptake, as described previously [23]. As expected, the putative LCFA uptake-blocking effects of the selected CD36 ligands can be best appreciated under conditions in which CD36 has a large contribution to the LCFA uptake rate in cardiomyocytes. Therefore we also tested the ability of these CD36 ligands to inhibit LCFA uptake into cardiomyocytes treated with the $\mathrm{F}_{1} \mathrm{~F}_{0}$ ATPase inhibitor oligomycin, because oligomycin treatment is known to enhance the contribution of CD36 to total LCFA uptake into rat cardiomyocytes from approximately $50 \%$ to $>80 \%$ [28]. In agreement with the effects under basal conditions, only SSO and anti-CD36-cl63 significantly inhibited LCFA uptake under oligomycin stimulation (Figure 1A). We then tested lower and higher concentrations of the CD36 ligands used on LCFA uptake in cardiomyocytes. In the case of EP80317 and hexarelin, higher concentrations impaired cell viability (results not shown). In the case of anti-CD36-cl10E10 (results not shown) and anti-CD36-cl63 (Figure 1B), no further inhibitory effect was observed at higher concentrations, whereas lower anti-CD36cl63 concentrations did not significantly inhibit LCFA uptake. In contrast with LCFA uptake, both SSO and anti-CD36-cl63 did not inhibit basal or oligomycin-stimulated glucose uptake (Figure 1), thereby providing evidence that their inhibitory effects on cardiac substrate uptake are selective for LCFA uptake. Because SSO is not suitable as a long-term blocker of LCFA uptake [24], we selected anti-CD36-cl63 $(0.83 \mu \mathrm{g} / \mathrm{ml})$ to chronically inhibit palmitate uptake into primary cardiomyocyte cultures.

\section{Short-term insulin effect on substrate uptake disappears after 30 min}

To assay insulin-stimulated glucose and LCFA uptake, we treated cardiomyocytes with insulin for $15 \mathrm{~min}$ prior to substrate-uptake measurements. However, in the case of culturing cardiomyocytes in HI medium for 2 days, chronic and short-term insulin effects might be present at the same time. To fully appreciate the chronic effects of insulin on Akt phosphorylation and substrate uptake, the short-term effect of insulin must have completely disappeared. Therefore we determined the disappearance time of short-term insulin effects on glucose and, for comparison, on LCFA uptake into basally cultured cardiomyocytes. Cardiomyocytes were stimulated with insulin ( $100 \mathrm{nM}$ ) for $15 \mathrm{~min}$ and directly assayed for substrate uptake or the stimulus medium containing insulin was washed away and substrate uptake was measured at several time points (Figure 2). First, insulin significantly increased both glucose and palmitate uptake rates (Figure 2). Secondly, glucose uptake returned to basal levels after $15 \mathrm{~min}$ and palmitate uptake returned to basal levels after $30 \mathrm{~min}$. Therefore, in the following experiments, cells were washed after $48 \mathrm{~h}$ of culturing. Then, control medium was added to all wells, and we waited for $30 \mathrm{~min}$ before starting insulin-sensitivity measurements.

\section{Establishment of lipid-loaded and insulin-resistant cardiomyocytes with decreased contractile activity}

Cardiomyocytes were exposed to HI or HP medium to induce myocellular insulin resistance. One of the initial steps in acquisition of myocellular insulin resistance is the permanent relocation of CD36 to the sarcolemma [34]. The presence 
A

\section{Palmitate Uptake 믐 ${ }^{\text {Basal }}$ Oligomycin Glucose Uptake}

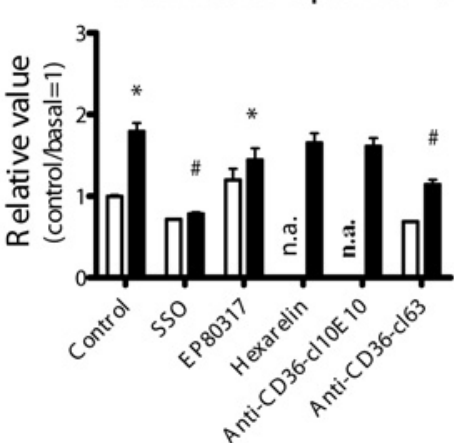

B

Palmitate Uptake

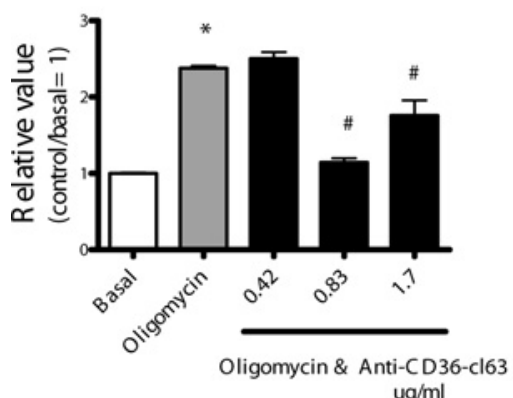

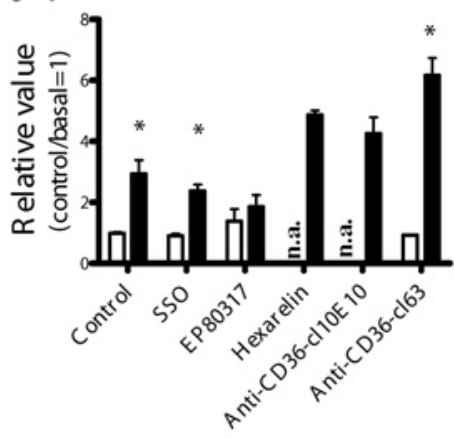

Glucose Uptake

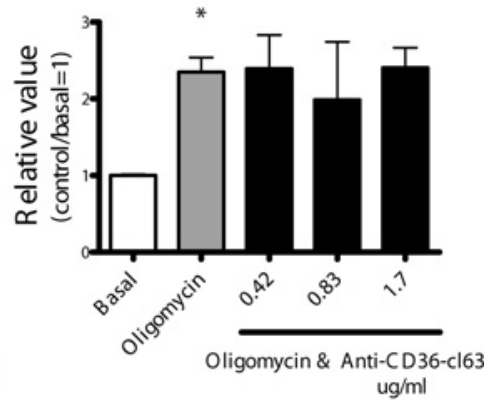

Figure 1 Effects of selected CD36 ligands on basal and oligomycin-stimulated glucose and LCFA uptake into cardiomyocytes

(A) Cardiomyocytes were pre-incubated with CD36 ligands for $20 \mathrm{~min}$ (control, 20 $\mu \mathrm{M}$ hexarelin, $0.5 \mathrm{mM}$ SS0, $100 \mu \mathrm{M} \mathrm{EP80317,} 0.83 \mu \mathrm{g} / \mathrm{ml}$ anti-CD36-cl63 and 1.7 $\mu \mathrm{g} / \mathrm{ml}$ anti-CD36-cl10E10). Next, oligomycin $(5 \mu \mathrm{M})$ was added for $20 \mathrm{~min}$, followed by measurement of the uptake of $\left[{ }^{3} \mathrm{H}\right] \mathrm{glucose}$ and $\left[{ }^{14} \mathrm{C}\right]$ palmitate $(n=5)$. (B) Cardiomyocytes were incubated for 20 min with different concentrations of anti-CD36-cl63 prior to oligomycin stimulation and measurement of substrate uptake $(n=3)$. Values are means + S.E.M. n.a., not analysed; ${ }^{*} P<0.05$ compared with basal; $\# P<0.05$ compared with oligomycin.

Palmitate Uptake

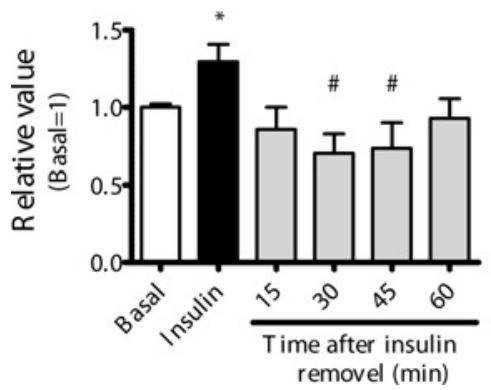

Glucose Uptake

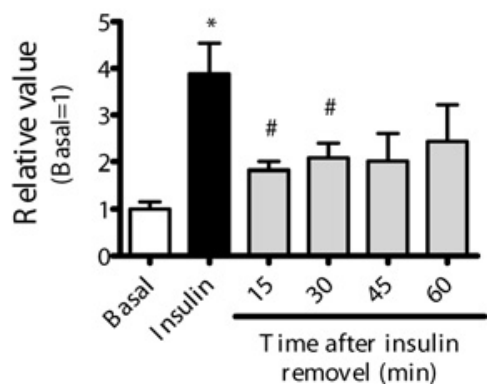

Figure 2 Disappearance of acute insulin effects on glucose and palmitate uptake into cardiomyocytes

At 90 min after seeding, cardiomyocytes were stimulated with insulin for $15 \mathrm{~min}$, and uptake of $\left[{ }^{3} \mathrm{H}\right] g$ lucose and $\left[{ }^{14} \mathrm{C}\right]$ palmitate was measured directly hereafter, or at the indicated time points after insulin removal. Values are means \pm S.E.M. $(n=5)$. ${ }^{*} P<0.05$ compared with basal; $\# P<0.05$ compared with insulin.

of sarcolemmal CD36 was measured in viable cells by twophoton microscopy. First, it was confirmed that this method could be successfully applied in our experimental setting, because short-term (15 min) insulin treatment of basally cultured cardiomyocytes promoted the well-recognized increase in CD36 presence at the sarcolemma (Figure 3A), which is due to translocation from intracellular stores [34]. Additionally, HI and HP medium enhanced the presence of sarcolemmal CD36 (Figure 3B). However, total (i.e. sum of intracellular and sarcolemmal) CD36 protein expression was not altered after culturing of cardiomyocytes in HI or HP medium (Figure 3C), implying that upon either of the insulin-resistance-inducing conditions CD36 is permanently relocated from intracellular stores to the sarcolemma. Additionally, both insulin-resistanceinducing media did not alter myocellular GLUT4 expression (Figure 3C).

Basally cultured cardiomyocytes displayed a 3.8-fold increase in glucose uptake and a 1.5-fold increase in palmitate uptake upon insulin treatment. Cardiomyocytes cultured in either HI or HP medium showed no change in basal glucose uptake (Figure 4A). In contrast, these cardiomyocytes exhibited elevated basal LCFA uptake (amounting to 1.4-fold and 1.6-fold respectively) 
A

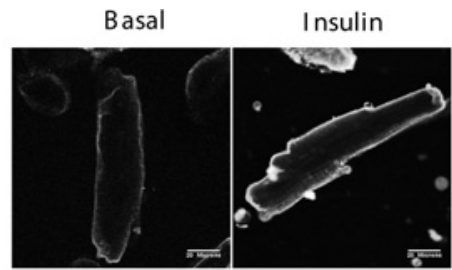

B

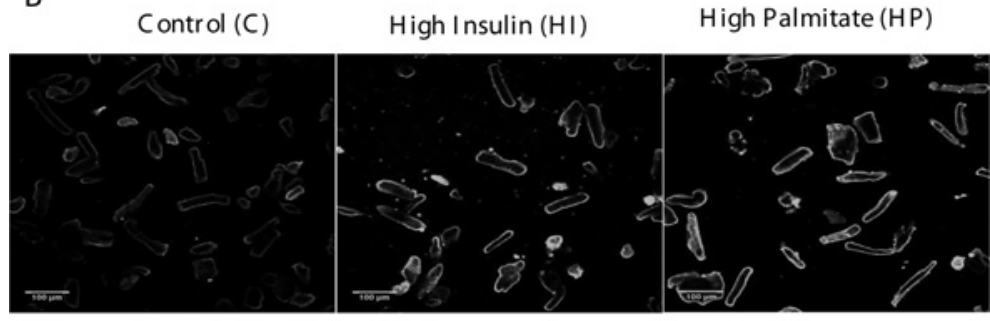

C

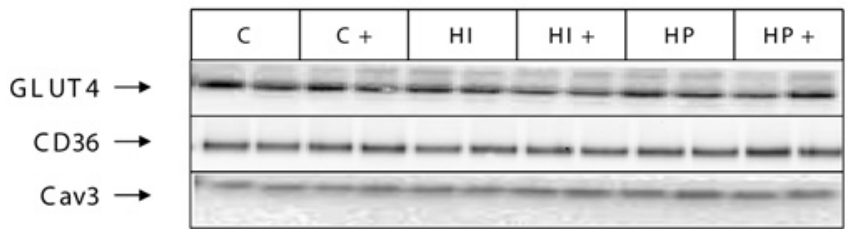

Figure 3 Effects of culturing under insulin-resistance-inducing conditions on cell-surface content and total expression levels of CD36 in cardiomyocytes

(A) For verification of the suitability of two-photon microscopy to visualize changes in cell-surface localization of CD36, cells were short-term (15 min) treated with $100 \mathrm{nM}$ insulin to positively confirm the well-described insulin-induced CD36-translocation event. CD36 was detected upon FITC labelling. Representative images are shown $(n=3)$. (B) Cardiomyocytes were cultured in control medium, or in $\mathrm{HI}$ or HP medium for $48 \mathrm{~h}$, and then used for microscopic detection of CD36 $(n=3)$. (C) Protein expression of GLUT4 and CD36, and caveolin 3 (Cav3, loading control) was measured in cell lysates from cardiomyocytes cultured in control (C), $\mathrm{Hl}$ or HP medium without or with $\left(\mathrm{C}^{+}, \mathrm{HI}^{+}, \mathrm{HP}^{+}\right) 0.83 \mu \mathrm{g} / \mathrm{ml}$ anti-CD36-cl63. Representative blots are shown $(n=3)$.

compared with basally cultured cells. In addition, cardiomyocytes cultured in either HI or HP medium displayed a loss of insulinstimulated glucose and LCFA uptake (Figure 4B).

For evaluation of insulin signalling, phosphorylation of Akt and its two direct substrates, AS160 and GSK3 $\beta$, was assessed. In basally cultured cardiomyocytes, short-term insulin addition increased Akt $\operatorname{Ser}^{473}$ phosphorylation, AS160 phosphorylation and GSK $3 \beta$ Ser $^{9}$ phosphorylation by 4.4 -fold, 3.8-fold and 2.5-fold respectively (Figure 5B). Insulin-stimulated signalling was completely lost in cardiomyocytes cultured in HI medium, and largely reduced in cardiomyocytes cultured in HP medium. In this latter instance, only a residual 3.1-fold insulin-stimulation of Akt $\operatorname{Ser}^{473}$ phosphorylation was observed, whereas induction of GSK3 $\beta$ and AS160 was completely abrogated (Figure 5B). These decreases in insulin signalling were not accompanied by changes in total expression of Akt or of downstream substrates (Supplementary Figure S1 at http://www.BiochemJ.org/bj/448/bj4480043add.htm).

With respect to myocellular lipid accumulation, cardiomyocytes cultured in HI or HP medium displayed increased triacylglycerol content (1.6-fold and 2.3-fold respectively) compared with basally cultured cardiomyocytes (Figure 6), but we did not observe changes in diacylglycerol stores (Figure 6).

To investigate whether exposure to HI or HP medium leads to physiological dysfunction of cardiomyocytes, we analysed the kinetics and amplitude of the contraction, and shortening and re-lengthening rates, as well as peak sarcomere shortening. Compared with basally cultured cardiomyocytes, peak sarcomere shortening decreased by $38 \%$ and $62 \%$ during culturing in $\mathrm{HI}$ and HP medium respectively (Figure 7A). Departure velocity and return velocity of contraction were also reduced by culturing in
HI and HP medium (departure velocity, $-45 \%$ and $-62 \%$ respectively; return velocity, $-65 \%$ and $-70 \%$ respectively). Intracellular $\mathrm{Ca}^{2+}$ fluxes (velocity of $\mathrm{Ca}^{2+}$ increases and decreases, and peak fura 2 fluorescence signal) were unchanged in cardiomyocytes cultured in either medium (Figure 7B).

Thus cardiomyocytes cultured in HI or HP medium displayed elevations in sarcolemmal CD36 presence, basal LCFA uptake and myocellular triacylglycerol content. In addition, cardiomyocytes cultured in either medium showed loss of insulin-stimulated substrate uptake, insulin signalling and sarcomere shortening, and hence displayed hallmark features of lipid-induced insulin resistance and contractile dysfunction.

\section{Effects of anti-CD36-cl63 treatment on prevention of lipid accumulation and development of insulin resistance}

Anti-CD36-cl63 was used to evaluate the effects of a blockade of CD36-mediated LCFA uptake on prevention of the development of insulin resistance and contractile dysfunction in cardiomyocytes cultured in HI or HP medium. Anti-CD36-cl63 was added at the start of the 2 days of culturing of cardiomyocytes under basal or insulin-resistance-inducing conditions, and was removed by washing the cardiomyocytes prior to the measurements of short-term glucose and palmitate uptake. The lack of an effect of anti-CD36-c163 on basal and insulin-stimulated palmitate uptake into basally cultured cardiomyocytes (Figure 4) indicates that this antibody has effectively been washed away (as shown with two-photon microscopy, see Supplementary Figure S2 at http://www.BiochemJ.org/bj/448/bj4480043add.htm), and suggests that there has been no compensatory up-regulation of CD36 (in agreement with Figure 1C) or of other 


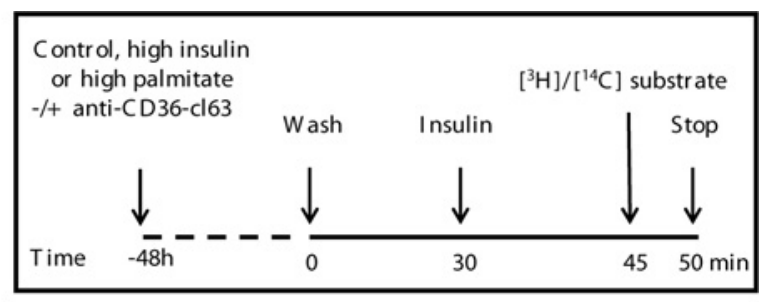

Glucose Uptake

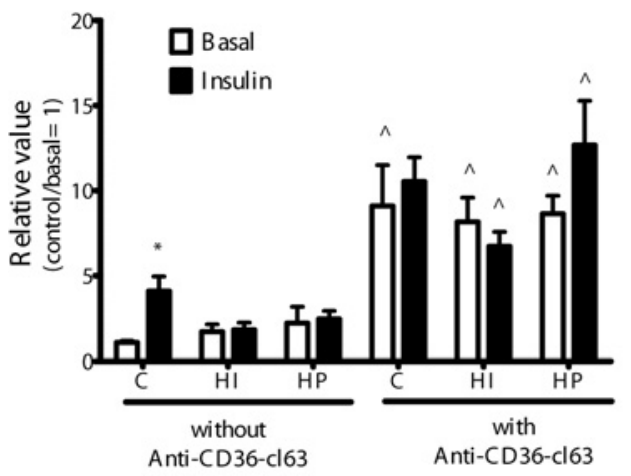

Palmitate Uptake

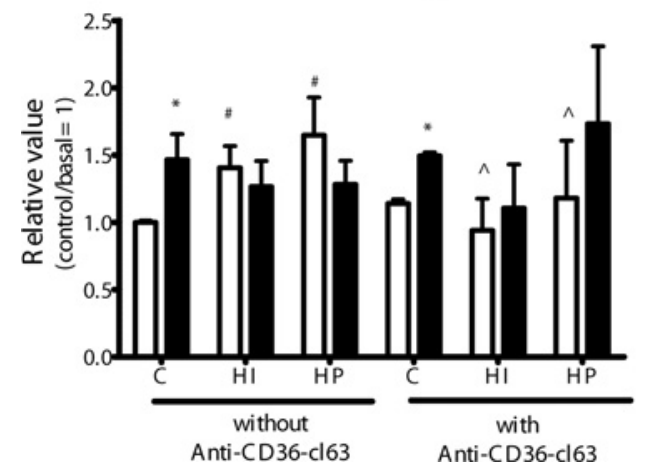

Figure 4 Effect of anti-CD36-c163 on substrate uptake into cardiomyocytes cultured under insulin-resistance-inducing conditions

Cardiomyocytes were cultured in control (C), HI or HP medium in the absence or presence of $0.83 \mu \mathrm{g} / \mathrm{ml}$ anti-CD36-cl63. Upon 2 days culturing, cells were allowed to recover for $30 \mathrm{~min}$ prior to short-term (15 min) insulin (100 nM) addition and subsequent measurement of uptake of $\left[{ }^{3} \mathrm{H}\right] \mathrm{glucose}$ and $\left[{ }^{14} \mathrm{C}\right]$ palmitate. Values are means \pm S.E.M. $(n=5) .{ }^{*} P<0.05$, insulin effect; $\# P<0.05$, medium effect; $\wedge P<0.05$, anti-CD36 effect.

LCFA transporters. Furthermore, treatment with anti-CD36-cl36 increased basal glucose uptake into cardiomyocytes by 4-8fold under all three culturing conditions, and short-term insulin treatment did not stimulate glucose uptake further (Figure 4). Notably, treatment with anti-CD36-c163 prevented the increase in basal LCFA uptake in cardiomyocytes cultured in HI or HP medium. On the other hand, insulin-stimulated LCFA uptake was not restored by treatment with anti-CD36-cl63.

When investigating insulin signalling we observed that treatment with anti-CD36-cl63 increased basal Akt $\mathrm{Ser}^{473}$ phosphorylation under all three culture conditions (control, 3fold; HI medium, 3.2-fold; HP medium, 1.7-fold) (Figure 5). Treatment with anti-CD36-cl63 did not alter insulin-stimulated Akt phosphorylation in basally cultured cardiomyocytes, and did not prevent loss of insulin-stimulated Akt phosphorylation in cardiomyocytes cultured in HI medium. However, treatment with anti-CD36-cl63 was successful in preventing loss of insulinstimulated Akt phosphorylation in cardiomyocytes cultured in HP medium. Overall, changes in Akt $\mathrm{Ser}^{473}$ phosphorylation were largely reflected by changes in GSK $3 \beta \operatorname{Ser}^{9}$ phosphorylation, and to a lesser extent by changes in AS160 phosphorylation.

With respect to intramyocellular lipid accumulation, treatment with anti-CD36-cl63 robustly reduced triacylglycerol content in cardiomyocytes cultured in control medium, and completely prevented the increase in triacylglycerol storage upon culturing in HI or HP medium (Figure 6). There was no effect of treatment with anti-CD36-cl63 on myocellular diacylglycerol content (Figure 6).

With respect to parameters of contractile function, treatment with the anti-CD36-cl63 had no effect on sarcomere shortening or intracellular $\mathrm{Ca}^{2+}$ oscillations in basally cultured cardiomyocytes. Treatment of primary cardiomyocytes with anti-CD36-cl63 totally or largely prevented the decrease in peak sarcomere shortening in HI- or HP-cultured cardiomyocytes respectively (Figure 7). Additionally, shortening and relengthening rates were partially retained upon treatment of HI-cultured cardiomyocytes with anti-CD36-cl63. In contrast, intracellular $\mathrm{Ca}^{2+}$ oscillations were not altered by treatment with anti-CD36-cl63 (Figure 7).

We also tested the effects of anti-CD36-c110E10, which detects CD36 on Western blot (Supplementary Figure S3 at http://www.BiochemJ.org/bj/448/bj4480043add.htm), but which failed to block short-term LCFA uptake (Figure 1A), on glucose uptake and contractile function in cardiomyocytes cultured in basal, HI and HP media. In contrast with anti-CD36-cl63, antiCD36-cl10E10 did not increase basal glucose uptake under the three culturing conditions or restore peak sarcomere shortening in HI-cultured cardiomyocytes (Supplementary Figure S3). Hence, the beneficial effects of anti-CD36-cl63 cardiomyocytes exposed to lipotoxic conditions are probably not due to simply binding to $\mathrm{CD} 36$, but rather due to a blockade of the transport function of CD36.

In summary, treatment of cardiomyocytes cultured in $\mathrm{HI}$ or HP medium with anti-CD36-cl63 prevented lipid accumulation and lipid-induced contractile dysfunction. However, treatment with anti-CD36-cl63 only protected insulin signalling in cardiomyocytes cultured in HP medium, and not when cultured in HI medium.

\section{DISCUSSION}

In the present paper we described the preventive action of a pharmacological blockade of LCFA uptake in the development of insulin resistance and contractile dysfunction in cardiomyocytes. Although there are many studies reporting on the ability of lipids to decrease insulin signalling and to alter substrate utilization in cellular systems, including cardiomyocytes, none of these studies have proposed to restore the maladaptive changes by blocking protein-mediated cellular LCFA uptake. In the present study, we investigated the suitability of CD36 as a target to restore insulin sensitivity and contractile parameters in cultures of cardiomyocytes exposed to insulin-resistanceinducing conditions. First, a variety of structurally unrelated compounds reported to inhibit CD36 function were screened for their ability to inhibit LCFA uptake into primary cardiomyocytes. Secondly, we established that cardiomyocytes cultured in $\mathrm{HI}$ or HP medium displayed key features of lipid-induced insulin resistance [34]. Finally, we demonstrated that inhibition of CD36mediated LCFA uptake was able to prevent lipid accumulation and contractile dysfunction in cardiomyocytes cultured under insulinresistance-inducing conditions. 


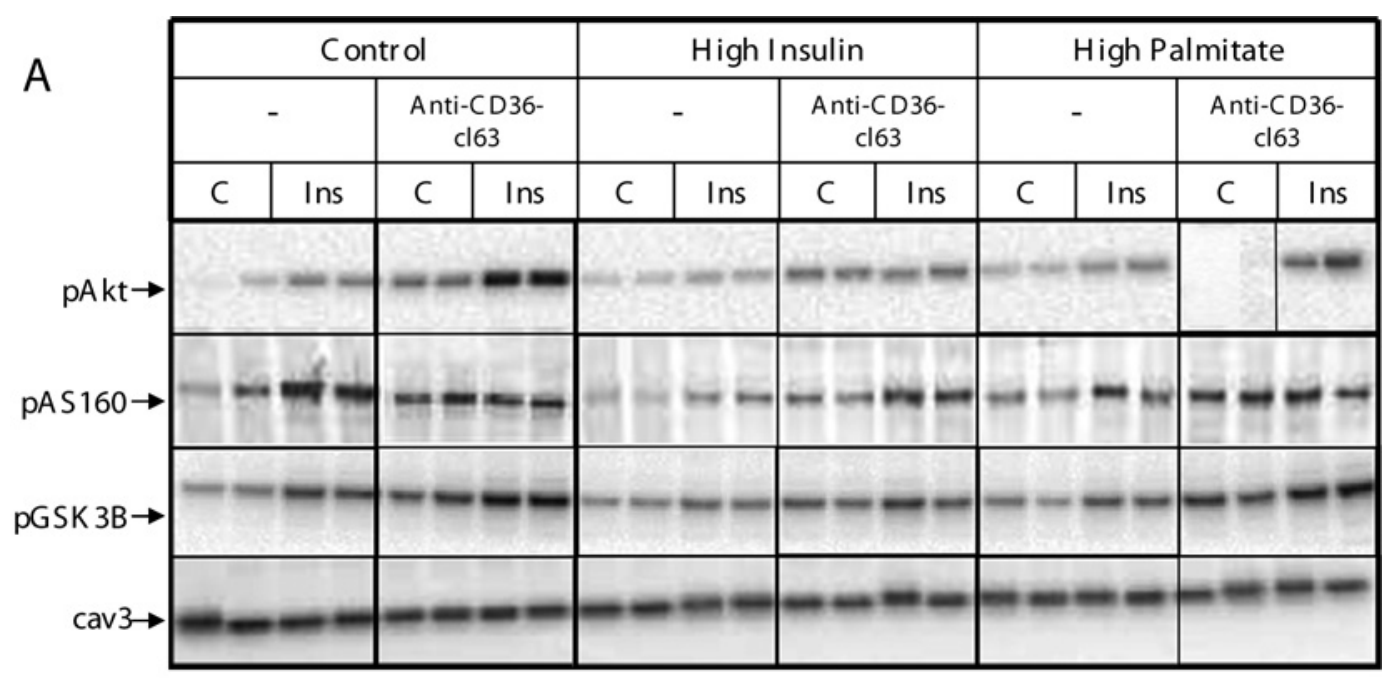

B

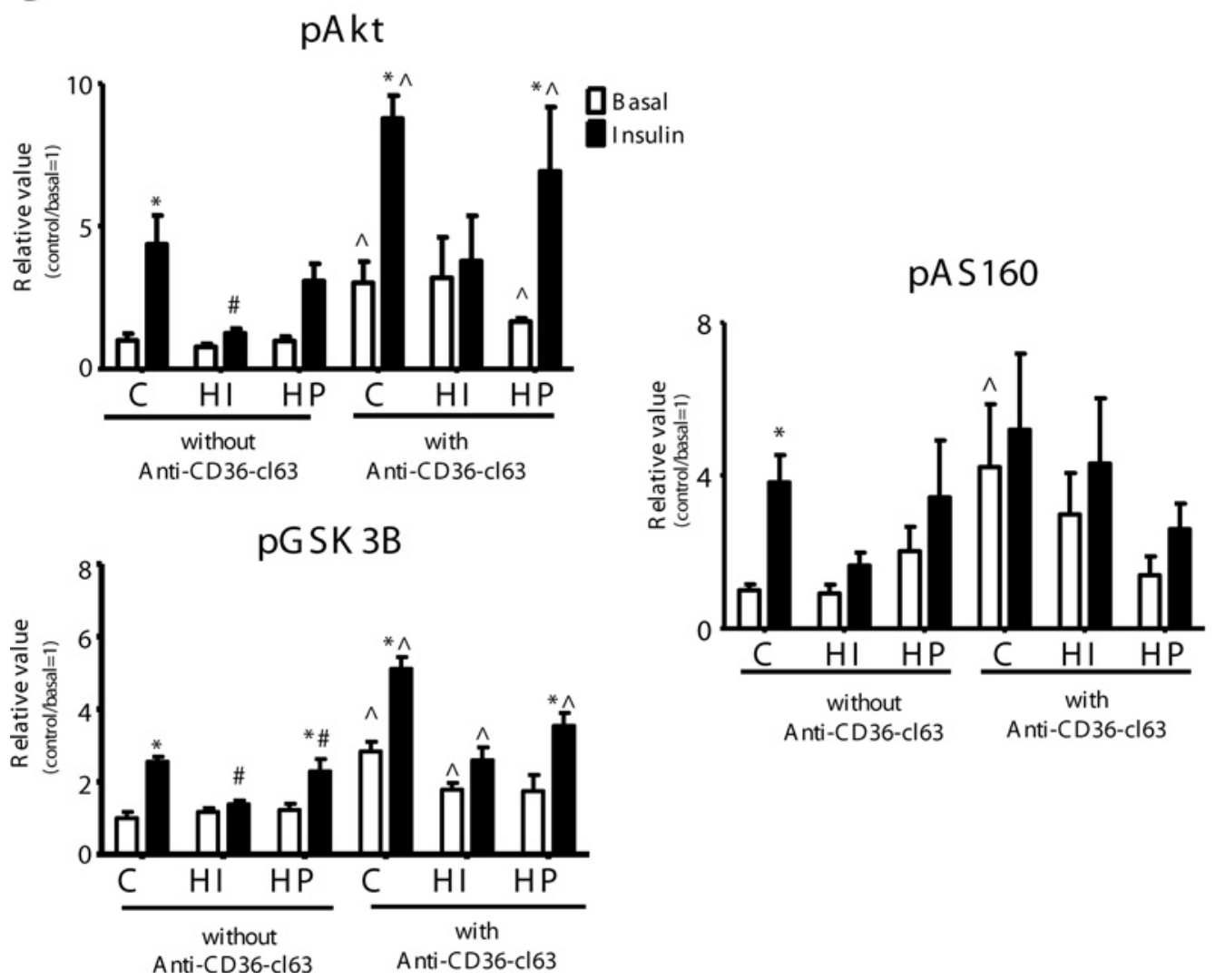

Figure 5 Effect of anti-CD36-cI63 on insulin signalling in cardiomyocytes cultured under insulin-resistance-inducing conditions

Cardiomyocytes were cultured in control (C), HI or HP medium in the absence or presence of $0.83 \mu \mathrm{g} / \mathrm{ml}$ anti-CD36-cl63. Upon 2 days culturing, cells were allowed to recover for 30 min prior to short-term (15 min) insulin (100 nM) addition and subsequent Western blotting for phosphorylation of Akt (pAkt), AS160 (pAS160) and GSK3 $\beta$ (pGSK3 $\beta$ ). Representative blots are shown in (A). Quantification of the signals is shown in (B). Values are means \pm S.E.M. $(n=5)$. ${ }^{*} P<0.05$, insulin effect; $\# P<0.05$, medium effect; $\wedge P<0.05$, anti-CD36 effect.

\section{Anti-CD36-cl63 potently inhibits LCFA uptake into primary cardiomyocytes}

SSO is the most widely established inhibitor of CD36-mediated LCFA uptake, but its use in long-term incubations is not feasible because of its relatively short half-life in aqueous solutions [24]. Nonetheless, the use of SSO in short-term LCFA uptake studies confirmed that maximally stimulated LCFA uptake in these primary cardiomyocytes is largely CD36-dependent. The CD36specific thrombospondin-binding peptide inhibitors hexarelin and EP80317 did not affect LCFA uptake, demonstrating that the thrombospondin-binding domain of CD36 is not involved in LCFA transport or does not overlap with the LCFA-binding pocket of CD36 [35,36]. Hence both peptides are likely to be 

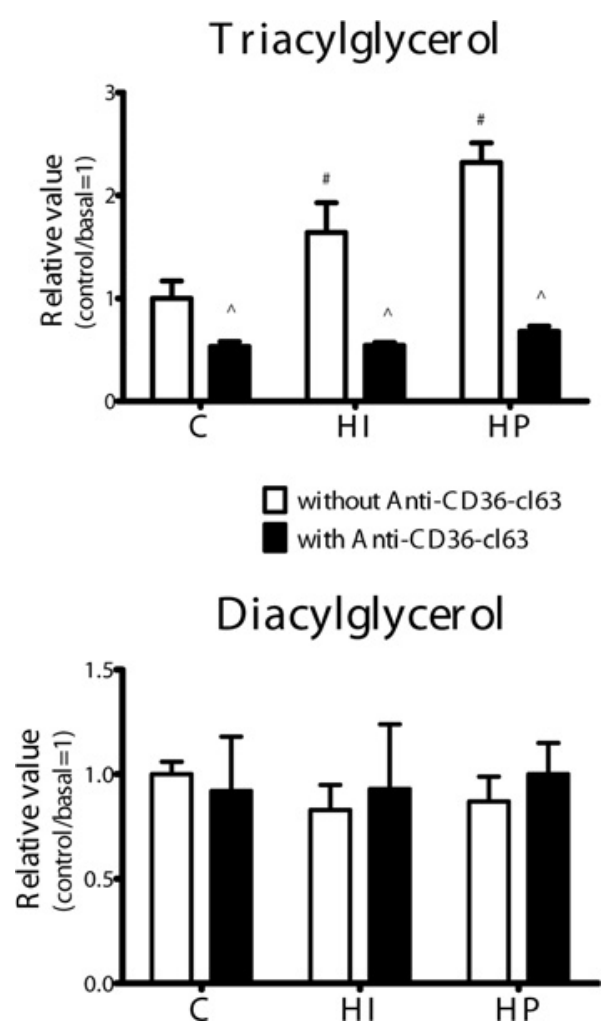

Figure 6 Effect of anti-CD36-cl63 on lipid accumulation in cardiomyocytes cultured under insulin-resistance-inducing conditions

Cardiomyocytes were cultured in control, $\mathrm{HI}$ or HP medium in the absence or presence of $0.83 \mu \mathrm{g} / \mathrm{ml}$ anti-CD36-cl63. After 2 days culturing, cardiomyocytes were lysed, and used for measurement of triacylglycerol and diacylglycerol content via high-performance-TLC. Values are means \pm S.E.M. $(n=5) . \# P<0.05$, medium effect; $\wedge P<0.05$, anti-CD36 effect.

unsuitable for protection against myocellular lipid overload. The use of CD36-specific mAbs proved to be more promising in terms of blocking LCFA uptake. Specifically, anti-CD36-c163 treatment inhibited maximally stimulated LCFA uptake by $>30 \%$ (Figure 1). However, frequently used anti-CD36 mAbs, such as clone MO25 and clone OKM5 [37], did not appear to affect LCFA uptake. Whereas SSO inhibited LCFA uptake by $>70 \%$ [38] in heart giant sarcolemmal vesicles, both of these latter anti-CD36 mAbs were without effect on LCFA uptake in these vesicles (J.J.F.P. Luiken and A. Bonen, unpublished work). Taken together, the results suggest that the anti-CD36-c163 is a valuable in vitro tool to test whether CD36-mediated LCFA uptake would be a target for offering protection to lipid-overloaded cardiomyocytes against the development of insulin resistance and contractile dysfunction.

\section{Development of a cardiomyocyte model for lipid-induced insulin resistance}

Long-term incubation of cell lines or primary cell cultures with saturated LCFA species has been shown to induce insulin resistance at the level of decreased insulin signalling and/or decreased insulin-stimulated glucose uptake [39-41]. However, long-term effects on LCFA transport, transporters and storage have not yet been investigated. Chronic insulin stimulation has also been used to induce insulin resistance in cardiomyocyte cultures [26] but, again, LCFA transport and transporters were not measured. In the present study, chronic insulin treatment as well as chronic palmitate treatment of cardiomyocyte cultures enhanced the presence of CD36 at the sarcolemma in concordance with elevated basal LCFA uptake and triacylglycerol accumulation. Simultaneously, insulin-stimulated phosphorylation of proteins in the insulin signalling cascade and insulin-stimulated glucose and LCFA uptake were lost or markedly reduced in chronic insulinor palmitate-treated cardiomyocytes. These results indicate that both chronic conditions induce key features of insulin resistance in this in vitro cardiomyocyte model. Yet there are some subtle differences in insulin-treated and palmitate-treated cardiomyocytes concerning these features of insulin resistance: (i) lipid accumulation in palmitate-treated cells is 2-fold greater than in insulin-treated cells, whereas inhibition of insulin signalling is less extensive in palmitate-treated cells, and (ii) inhibition of insulin-stimulated substrate uptake is almost identical in both insulin- and palmitate-treated cardiomyocytes. This demonstrates that there is no linear relationship between lipid accumulation, impairment of insulin signalling and of insulinstimulated glucose uptake. Another striking feature of the HI- and HP-cultured cells is that the increase in myocellular triacylglycerol storage is not accompanied by increased diacylglycerol levels. This is different from the concomitant increases in myocellular diacylglycerol and triacylglycerol contents in rodents fed with high-fat diets for several weeks (e.g. see [13]). This is probably related to the much shorter (i.e. $48 \mathrm{~h}$ ) exposure of the cells to lipotoxic conditions, in which time the diacylglycerol and triacylglycerol stores might not have reached full equilibrium yet. However, importantly, given that the cells are insulin resistant, it can be deduced that diacylglycerols do not contribute to the acquisition of insulin resistance in these cultured cardiomyocytes.

With respect to cardiomyocyte contractility, culturing of cardiomyocytes in HI or HP medium impaired contractile amplitude. This is in agreement with recent findings that exposure of freshly isolated adult mouse cardiomyocytes to palmitate rapidly reduced unloaded fractional cell shortening [27], and in line with the currently accepted idea that insulin resistance is causal to contractile dysfunction [42]. There is more controversy about the association of insulin resistance with disturbance of $\mathrm{Ca}^{2+}$ dynamics. In our experiments $\mathrm{Ca}^{2+}$ oscillations were unchanged in cells cultured in HI and HP medium. This is in agreement with the lack of change in kinetics and amplitude of $\mathrm{Ca}^{2+}$ transients in cardiomyocytes from mice fed a high-fat diet [43]. However, cardiomyocytes from insulin resistant sucrosefed mice and $o b / o b$ mice displayed decreased $\mathrm{Ca}^{2+}$ oscillations $[44,45]$. Nonetheless, sarcomere shortening is considered as a better marker of mechanical output for evaluating cardiomyocyte function [46]. Interestingly, the alterations in contractile function were proportional to the amount of myocellular triacylglycerol accumulation, because HP-cultured cardiomyocytes showed greater dysfunction and greater triacylglycerol accumulation than in HI-cultured cells. This supports the concept that myocellular accumulation of lipids is causal to contractile dysfunction.

In conclusion, both HI and HP medium provide suitable culturing conditions for inducing insulin resistance and contractile dysfunction in cardiomyocytes via myocellular lipid overload.

\section{Inhibition of CD36-mediated LCFA uptake prevents reduction of insulin sensitivity and contractile function in lipid-overloaded cardiomyocytes}

The main purpose of the present study was to prevent the development of lipid-induced insulin resistance and contractile dysfunction by inhibition of CD36-mediated LCFA uptake.

First, we investigated the metabolic effects of inhibition of CD36-mediated LCFA uptake in basally cultured insulin-sensitive 


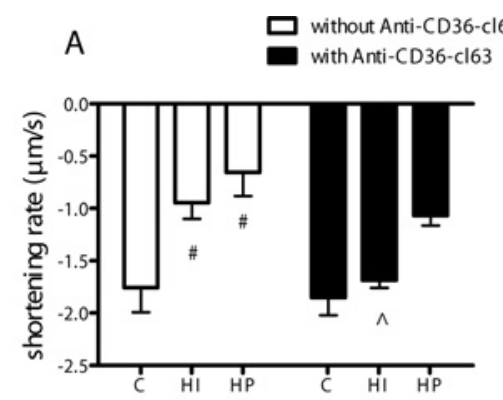

\section{B}
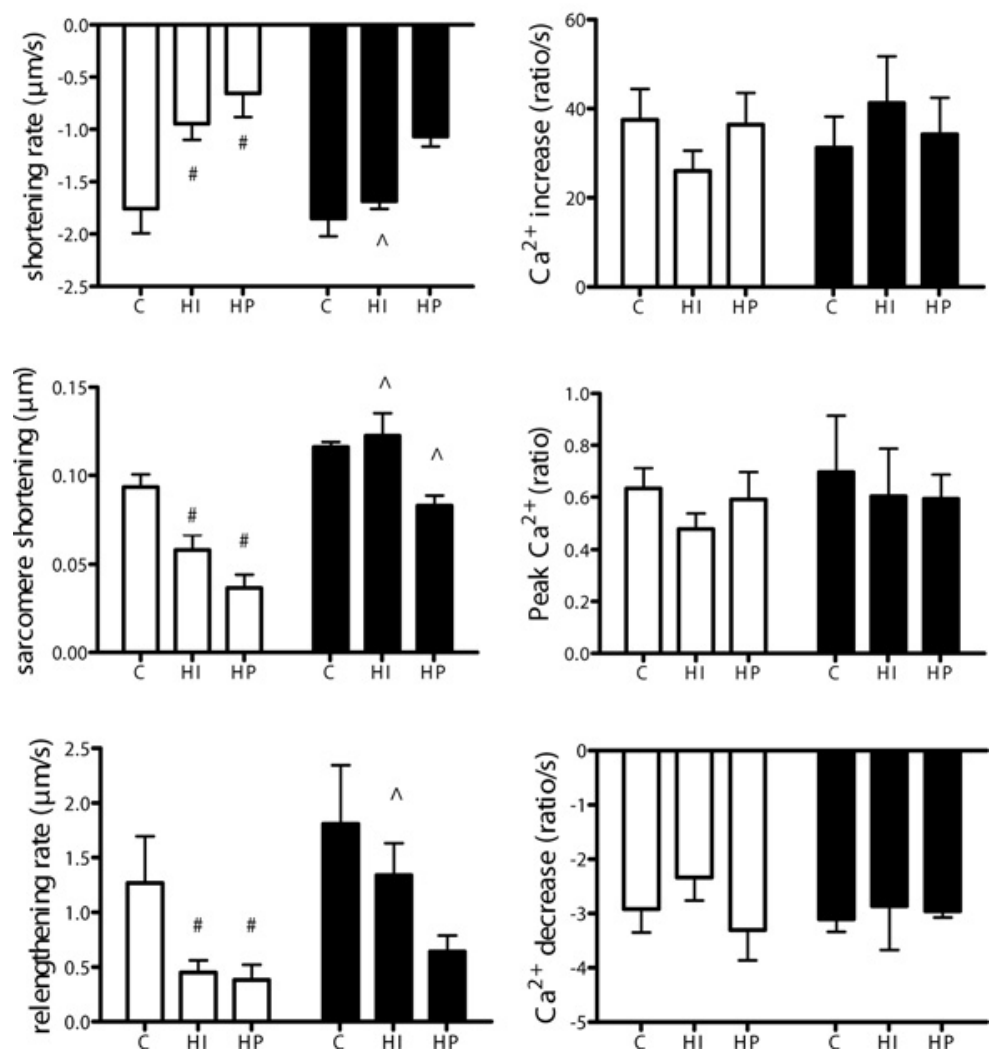

Figure 7 Effect of anti-CD36-cI63 on contractile functions of cardiomyocytes cultured under insulin-resistance-inducing conditions

Cardiomyocytes were cultured in control, $\mathrm{HI}$ or HP in the absence or presence of $0.83 \mu \mathrm{g} / \mathrm{ml}$ anti-CD36-cl63. After 2 days culturing, cardiomyocytes were used for analysis of the following parameters: (A) sarcomere shortening and (B) $\mathrm{Ca}^{2}+$ fluxes. (A) Departure velocity of contraction, peak sarcomere shortening and return velocity of contraction. (B) Velocity of cytosolic $\mathrm{Ca}^{2+}$ increases, peak fura 2 fluorescence signal and velocity of cytosolic $\mathrm{Ca}^{2+}$ decreases. Values are means \pm S.E.M. for at least ten independent experiments. $\# P<0.05$, medium effect; $\wedge P<0.05$, anti-CD36 effect.

cardiomyocytes. Treatment of basally cultured cardiomyocytes with anti-CD36-cl63 enhanced basal glucose uptake, and insulin did not stimulate glucose uptake further, suggesting that insulinstimulated glucose uptake contributes to increased basal glucose uptake in CD36-inhibited cardiomyocytes. This increased basal glucose uptake occurred in the absence of changes in GLUT4 expression, suggesting that a relocation of GLUT4 from intracellular insulin-responsive stores to the sarcolemma might explain this increase in basal glucose uptake. Furthermore, the anti-CD36cl63-induced increase in basal glucose uptake is likely to be due to a blockade of the transport function of CD36 rather than just binding to CD36. Namely, another anti-CD36 antibody, anti-CD36-cl10E10, unable to block the LCFA transport function, does not increase glucose uptake. This shows that merely binding to CD36 is not sufficient for a change in substrate switch towards glucose. Interestingly, the increase in basal glucose uptake was accompanied by an increase in phosphorylation of both Akt and its direct target AS160. Phosphorylation of AS160 will inhibits its Rab-GTPase activity, so that GLUT4 translocationmediating Rab proteins will be re-activated. Subsequently, GLUT4 will be liberated from retention within the intracellular stores. Remarkably, insulin-stimulated Akt phosphorylation was retained in basally cultured cardiomyocytes treated with antiCD36-c163, which is in contrast with the loss of insulin-stimulated glucose uptake. Perhaps in these cardiomyocytes GLUT4 is already completely depleted from the intracellular storage compartments, including the insulin-responsive stores, so that extra phosphorylation of Akt and of AS160 upon insulin addition would be futile in this respect. Another explanation could come from a recent study in which it was shown that Akt is not the ratelimiting step of insulin-induced glucose uptake [47]. However, insulin-stimulated glucose uptake in these anti-CD36-cl63treated cardiomyocytes was not further increased by additional stimulation of AMPK (AMP-activated protein kinase) signalling, whereas AMPK and insulin stimulation act synergistically in basally treated cardiomyocytes (Supplementary Figure S4 at http://www.BiochemJ.org/bj/448/bj4480043add.htm). This observation provides further evidence for the idea of depletion of intracellular GLUT4 storage upon a chronic CD36 blockade.

How anti-CD36-cl63 could trigger basal Akt phosphorylation in cardiomyocytes is a matter of speculation. Perhaps a pharmacological blockade of CD36 transport function prevents accumulation of LCFA metabolites that would inhibit kinases upstream of Akt or Akt itself. For instance, ceramides are known to directly inhibit Akt [48], and preventing their accumulation would therefore increase basal Akt phosphorylation. This would also assume that ceramide pools would more rapidly follow the changes in influx in LCFA than the diacylglycerols. Further research is needed to elucidate the molecular mechanisms behind increased basal Akt phosphorylation in anti-CD36-c163-treated cardiomyocytes.

Treatment of cardiomyocytes cultured under both insulinresistance-inducing conditions with anti-CD36-c163 enhanced basal Akt/GSK3 $\beta$ phosphorylation and basal glucose uptake 
in a similar manner to basally cultured cardiomyocytes treated with anti-CD36-cl63. More importantly, however, this treatment prevented myocellular lipid accumulation and loss of contractile function. Remarkably, treatment with anti-CD36-cl63 prevented the loss of insulin-stimulated Akt/GSK $3 \beta$ phosphorylation in cardiomyocytes cultured in HP medium, but was not able to retain insulin signalling in cardiomyocytes cultured in $\mathrm{HI}$ medium. We have no explanation for these selective preventive effects of anti-CD36-cl63 on insulin signalling and insulin-stimulated glucose uptake in one model of insulin resistant cardiomyocytes and not in the other. However, we may only conclude that the prevention of myocellular lipid accumulation can be connected to preservation of contractile function in the absence of preservation of insulin signalling. Possibly, the prevention of myocellular lipid accumulation might directly explain the anti-CD36 mAbmediated preservation of contractile function. Namely, increased depositing of lipid droplets in between the contractile fibres could directly inhibit contraction mechanics, which is then prevented by blocking CD36-mediated LCFA uptake. Alternatively, the prevention of myocellular lipid accumulation would prevent the activation of lipid-activated transcription factors that would otherwise induce an unfavourable switch in the expression pattern of isoforms of contractile proteins. However, we cannot exclude the possibility that the protective effects of the antiCD36 mAb are not related to inhibition of LCFA uptake. For instance, binding of anti-CD36-c163 to CD36 might induce intracellular signalling (e.g. Akt activation) that would directly or indirectly preserve contractile function of cardiomyocytes. Nonetheless, the finding that the anti-CD36 mAb prevents the reduction in contractile function in cardiomyocytes cultured under both insulin-resistance-inducing conditions provides powerful evidence that CD36 offers a suitable target to prevent the onset of cardiomyocyte dysfunction under these adverse conditions.

\section{Conclusions}

In addition to the previous findings in CD36-knockout mice that CD36-mediated LCFA uptake plays a key role in the development of lipid-induced insulin resistance and cardiac dysfunction $[17,18]$, the results of the present study illustrate that a pharmacological blockade of CD36 is a treatment strategy to counteract lipid accumulation and to protect against loss of cardiac function. Specifically, the blockade of CD36-mediated LCFA uptake caused a substrate switch towards glucose and prevented lipid accumulation and decreases in contractile function in two in vitro models of lipid-induced cardiac insulin resistance. Increased cardiac glucose uptake is known to be involved in the development of cardiomyocyte hypertrophy, suggesting that proper titration of anti-CD36 treatment is necessary to avoid a total shift of cardiomyocyte metabolism towards glucose utilization.

CD36 is known to have a number of different functions in different mammalian cell types. Therefore a pharmacological CD36 inhibitor that would interfere with all of these functions would be unfavourable. However, a hypothetical agent that would selectively block the sarcolemmal LCFA transport function of CD36 would not have these adverse side effects, and would therefore be optimally suited to improve cardiac lipid overload and contractile dysfunction in vivo. In this respect, it has been speculated that the LCFA-binding pocket in the extracellular domain of CD36 is not overlapping with the docking sites of thrombospondin and oxidized low-density lipoprotein [35]. Therefore the LCFA-binding pocket might be the subject of a novel drug design strategy to specifically block CD36 transport function.

\section{AUTHOR CONTRIBUTION}

Yeliz Angin and Laura Steinbusch designed and performed the experiments, analysed the data and wrote the paper. Peter Simons and Marc van Zandvoort reviewed the paper before submission. Sabrina Greulich, Nicole Hoebers, Will Coumans, Wino Wijnen and Kim Douma performed experiments. Margriet Ouwens, Michaela Diamant and Jan Glatz edited the paper before submission. Joost Luiken designed the experiments and edited the paper before submission.

\section{ACKNOWLEDGEMENTS}

We thank Lei Ding, Jurriaan Hodzelmans and Pascal Vroemen for their technical assistance.

\section{FUNDING}

This work was supported by the Dutch Diabetes Research Foundation [grant number 2006.00.044], the EU European Cooperation in the field of Scientific and Technical Research (COST) Action BM0602 (Adipose tissue: a key target for prevention of the metabolic syndrome), CTMM, the Center for Translational Molecular Medicine, project PREDICCt [grant number 01C-104], the Netherlands Heart Foundation and the Dutch Kidney Foundation.

\section{REFERENCES}

1 Rodrigues, B., Cam, M. C. and McNeill, J. H. (1998) Metabolic disturbances in diabetic cardiomyopathy. Mol. Cell. Biochem. 180, 53-57

2 Stanley, W. C., Lopaschuk, G. D. and McCormack, J. G. (1997) Regulation of energy substrate metabolism in the diabetic heart. Cardiovasc. Res. 34, 25-33

3 Carley, A. N. and Severson, D. L. (2005) Fatty acid metabolism is enhanced in type 2 diabetic hearts. Biochim. Biophys. Acta 1734, 112-126

4 Menard, S. L., Croteau, E., Sarrhini, O., Gelinas, R., Brassard, P., Ouellet, R., Bentourkia M., van Lier, J. E., Des Rosiers, C., Lecomte, R. and Carpentier, A. C. (2010) Abnormal in vivo myocardial energy substrate uptake in diet-induced type 2 diabetic cardiomyopathy in rats. Am. J. Physiol. Endocrinol. Metab. 298, E1049-E1057

5 Tomita, T., Wilson, L. and Chiga, M. (1990) Idiopathic dilated cardiomyopathy: an evidence of abnormal lipid accumulation accumulation in myocardium. Am. J. Cardiovasc. Pathol. 3, 81-85

6 Chavez, J. A., Knotts, T. A., Wang, L. P., Li, G., Dobrowsky, R. T., Florant, G. L. and Summers, S. A. (2003) A role for ceramide, but not diacylglycerol, in the antagonism of insulin signal transduction by saturated fatty acids. J. Biol. Chem. 278, 10297-10303

7 Glatz, J. F. C., Luiken, J. J. F. P. and Bonen, A. (2010) Membrane fatty acid transporters as regulators of lipid metabolism: implications for metabolic disease. Physiol. Rev. 90, $367-417$

8 Bonen, A., Parolin, M. L., Steinberg, G. R., Calles-Escandon, J., Tandon, N. N., Glatz, J. F., Luiken, J. J., Heigenhauser, G. J. and Dyck, D. J. (2004) Triacylglycerol accumulation in human obesity and type 2 diabetes is associated with increased rates of skeletal muscle fatty acid transport and increased sarcolemmal FAT/CD36. FASEB J. 18, 1144-1146

9 Holloway, G. P., Benton, C. R., Mullen, K. L., Yoshida, Y., Snook, L. A., Han, X. X., Glatz, J. F., Luiken, J. J., Lally, J., Dyck, D. J. and Bonen, A. (2009) In obese rat muscle transport of palmitate is increased and is channeled to triacylglycerol storage despite an increase in mitochondrial palmitate oxidation. Am. J. Physiol. Endocrinol. Metab. 296, E738-E747

10 Savage, D. B., Petersen, K. F. and Shulman, G. I. (2007) Disordered lipid metabolism and the pathogenesis of insulin resistance. Physiol. Rev. 87, 507-520

11 Lopaschuk, G. D., Ussher, J. R., Folmes, C. D., Jaswal, J. S. and Stanley, W. C. (2010) Myocardial fatty acid metabolism in health and disease. Physiol. Rev. 90, 207-258

12 Steinbusch, L. K., Schwenk, R. W., Ouwens, D. M., Diamant, M., Glatz, J. F. and Luiken, J. J. (2011) Subcellular trafficking of the substrate transporters GLUT4 and CD36 in cardiomyocytes. Cell. Mol. Life Sci. 68, 2525-2538

13 Schwenk, R. W., Dirkx, E., Coumans, W. A., Bonen, A., Klip, A., Glatz, J. F. and Luiken, J. J. (2010) Requirement for distinct vesicle-associated membrane proteins in insulinand AMP-activated protein kinase (AMPK)-induced translocation of GLUT4 and CD36 in cultured cardiomyocytes. Diabetologia $\mathbf{5 3}, 2209-2219$

14 Martin, S., Slot, J. W. and James, D. E. (1999) GLUT4 trafficking in insulin-sensitive cells. A morphological review. Cell. Biochem. Biophys. 30, 89-113

15 Habets, D. D. J. (2008) Regulation of cardiac long-chain fatty acid and glucose utilization: studies from genetically manipulated mice. Ph.D. Thesis, Maastricht University, The Netherlands 
16 Coort, S. L., Luiken, J. J., van der Vusse, G. J., Bonen, A. and Glatz, J. F. (2004) Increased FAT (fatty acid translocase)/CD36-mediated long-chain fatty acid uptake in cardiac myocytes from obese Zucker rats. Biochem. Soc. Trans. 32, 83-85

17 Ouwens, D. M., Diamant, M., Fodor, M., Habets, D. D., Pelsers, M. M., El Hasnaoui, M., Dang, Z. C., van den Brom, C. E., Vlasblom, R., Rietdijk, A. et al. (2007) Cardiac contractile dysfunction in insulin-resistant rats fed a high-fat diet is associated with elevated CD36-mediated fatty acid uptake and esterification. Diabetologia $\mathbf{5 0}$, 1938-1948

18 Steinbusch, L. K., Luiken, J. J., Vlasblom, R., Chabowski, A., Hoebers, N. T., Coumans, W. A., Vroegrijk, I. O., Voshol, P. J., Ouwens, D. M., Glatz, J. F. and Diamant, M. (2011) Absence of fatty acid transporter CD36 protects against Western-type diet-related cardiac dysfunction following pressure overload in mice. Am. J. Physiol. Endocrinol. Metab. 301, E618-E627

19 Yang, J., Sambandam, N., Han, X., Gross, R. W., Courtois, M., Kovacs, A., Febbraio, M., Finck, B. N. and Kelly, D. P. (2007) CD36 deficiency rescues lipotoxic cardiomyopathy. Circ. Res. 100, 1208-1217

20 Collot-Teixeira, S., Martin, J., McDermott-Roe, C., Poston, R. and McGregor, J. L. (2007) CD36 and macrophages in atherosclerosis. Cardiovasc. Res. 75, 468-477

21 Kennedy, D. J., Kuchibhotla, S., Westfall, K. M., Silverstein, R. L., Morton, R. E. and Febbraio, M. (2011) A CD36-dependent pathway enhances macrophage and adipose tissue inflammation and impairs insulin signalling. Cardiovasc. Res. 89, 604-613

22 Sun, B., Boyanovsky, B. B., Connelly, M. A., Shridas, P., van der Westhuyzen, D. R. and Webb, N. R. (2007) Distinct mechanisms for OxLDL uptake and cellular trafficking by class B scavenger receptors CD36 and SR-BI. J. Lipid Res. 48, 2560-2570

23 Pettersson, I., Muccioli, G., Granata, R., Deghenghi, R., Ghigo, E., Ohlsson, C. and Isgaard, J. (2002) Natural (ghrelin) and synthetic (hexarelin) GH secretagogues stimulate $\mathrm{H} 9 \mathrm{c} 2$ cardiomyocyte cell proliferation. J. Endocrinol. 175, 201-209

24 Coort, S. L., Willems, J., Coumans, W. A., van der Vusse, G. J., Bonen, A., Glatz, J. F. and Luiken, J. J. (2002) Sulfo-N-succinimidyl esters of long chain fatty acids specifically inhibit fatty acid translocase (FAT/CD36)-mediated cellular fatty acid uptake. Mol. Cell. Biochem. 239, 213-219

25 Kusaka, Y., Tanaka, T., Okamoto, F., Terasaki, F., Matsunaga, Y., Miyazaki, H. and Kawamura, K. (1995) Effect of sulfo-N-succinimidyl palmitate on the rat heart: myocardial long-chain fatty acid uptake and cardiac hypertrophy. J. Mol. Cell. Cardiol. 27, 1605-1612

26 Bertrand, L., Ginion, A., Beauloye, C., Hebert, A. D., Guigas, B., Hue, L. and Vanoverschelde, J. L. (2006) AMPK activation restores the stimulation of glucose uptake in an in vitro model of insulin-resistant cardiomyocytes via the activation of protein kinase B. Am. J. Physiol. Heart Circ. Physiol. 291, H239-H250

27 Haim, T. E., Wang, W., Flagg, T. P., Tones, M. A., Bahinski, A., Numann, R. E., Nichols, C. G. and Nerbonne, J. M. (2010) Palmitate attenuates myocardial contractility through augmentation of repolarizing Kv currents. J. Mol. Cell. Cardiol. 48, 395-405

28 Luiken, J. J., Coort, S. L., Willems, J., Coumans, W. A., Bonen, A., van der Vusse, G. J. and Glatz, J. F. (2003) Contraction-induced fatty acid translocase/CD36 translocation in rat cardiac myocytes is mediated through AMP-activated protein kinase signaling. Diabetes 52, 1627-1634

29 Steinbusch, L. K., Wijnen, W., Schwenk, R. W., Coumans, W. A., Hoebers, N. T., Ouwens, D. M., Diamant, M., Bonen, A., Glatz, J. F. and Luiken, J. J. (2010) Differential regulation of cardiac glucose and fatty acid uptake by endosomal $\mathrm{pH}$ and actin filaments. Am. J. Physiol. Cell. Physiol. 298, C1549-C1559

30 Luiken, J. J., van Nieuwenhoven, F. A., America, G., van der Vusse, G. J. and Glatz, J. F. (1997) Uptake and metabolism of palmitate by isolated cardiac myocytes from adult rats: involvement of sarcolemmal proteins. J. Lipid Res. 38, 745-758

31 Bonen, A., Luiken, J. J., Arumugam, Y., Glatz, J. F. and Tandon, N. N. (2000) Acute regulation of fatty acid uptake involves the cellular redistribution of fatty acid translocase. J. Biol. Chem. 275, 14501-14508

Received 9 January 2012/14 June 2012; accepted 10 July 2012

Published as BJ Immediate Publication 10 July 2012, doi:10.1042/BJ20120060
32 Greulich, S., De Wiza, D. H., Preilowksi, S., Ding, Z., Mueller, H., Langin, D., Jaquet, K., Ouwens, D. M. and Eckel, J. (2011) Secretory products of guinea pig epicardial fat induce insulin resistance and impair primary adult rat cardiomyocyte function. J. Cell. Mol. Med. 15, 2399-2410

33 Alkhateeb, H., Chabowski, A., Glatz, J. F., Luiken, J. F. and Bonen, A. (2007) Two phases of palmitate-induced insulin resistance in skeletal muscle: impaired GLUT4 translocation is followed by a reduced GLUT4 intrinsic activity. Am. J. Physiol. Endocrinol. Metab. 293 E783-E793

34 Coort, S. L., Bonen, A., van der Vusse, G. J., Glatz, J. F. and Luiken, J. J. (2007) Cardiac substrate uptake and metabolism in obesity and type-2 diabetes: role of sarcolemmal substrate transporters. Mol. Cell. Biochem. 299, 5-18

35 Silverstein, R. L. and Febbraio, M. (2009) CD36, a scavenger receptor involved in immunity, metabolism, angiogenesis, and behavior. Sci. Signaling 2, re3

36 Nergiz-Unal, R., Rademakers, T., Cosemans, J. M. and Heemskerk, J. W. (2011) CD36 as a multiple-ligand signaling receptor in atherothrombosis. Cardiovasc. Hematol. Agents Med. Chem. 9, 42-55

37 Yamamoto, N., Ikeda, H., Tandon, N. N., Herman, J., Tomiyama, Y., Mitani, T., Sekiguchi, S., Lipsky, R., Kralisz, U. and Jamieson, G. A. (1990) A platelet membrane glycoprotein (GP) deficiency in healthy blood donors: Naka-platelets lack detectable GPIV (CD36). Blood 76, 1698-1703

38 Luiken, J. J., Turcotte, L. P. and Bonen, A. (1999) Protein-mediated palmitate uptake and expression of fatty acid transport proteins in heart giant vesicles. J. Lipid Res. $\mathbf{4 0}$, 1007-1016

39 Dimopoulos, N., Watson, M., Sakamoto, K. and Hundal, H. S. (2006) Differential effects of palmitate and palmitoleate on insulin action and glucose utilization in rat L6 skeletal muscle cells. Biochem. J. 399, 473-481

40 Pickersgill, L., Litherland, G. J., Greenberg, A. S., Walker, M. and Yeaman, S. J. (2007) Key role for ceramides in mediating insulin resistance in human muscle cells. J. Biol. Chem. 282, 12583-12589

41 Ragheb, R., Shanab, G. M., Medhat, A. M., Seoudi, D. M., Adeli, K. and Fantus, I. G. (2009) Free fatty acid-induced muscle insulin resistance and glucose uptake dysfunction: evidence for PKC activation and oxidative stress-activated signaling pathways. Biochem. Biophys. Res. Commun. 389, 211-216

42 Ren, J., Porter, J. E., Wold, L. E., Aberle, N. S., Muralikrishnan, D. and Haselton, J. R. (2004) Depressed contractile function and adrenergic responsiveness of cardiac myocytes in an experimental model of Parkinson disease, the MPTP-treated mouse. Neurobiol. Aging 25, 131-138

43 Howarth, F. C., Qureshi, M. A., Gbewonyo, A. J., Tariq, S. and Adeghate, E. (2005) The progressive effects of a fat enriched diet on ventricular myocyte contraction and intracellular $\mathrm{Ca}^{2+}$ in the C57BL/6J mouse. Mol. Cell. Biochem. 273, 87-95

44 Fauconnier, J., Lanner, J. T., Zhang, S. J., Tavi, P., Bruton, J. D., Katz, A. and Westerblad, H. (2005) Insulin and inositol 1,4,5-trisphosphate trigger abnormal cytosolic $\mathrm{Ca}^{2+}$ transients and reveal mitochondrial $\mathrm{Ca}^{2+}$ handling defects in cardiomyocytes of $\mathrm{ob} / \mathrm{Ob}$ mice. Diabetes 54, 2375-2381

45 Dong, F., Fang, C. X., Yang, X., Zhang, X., Lopez, F. L. and Ren, J. (2006) Cardiac overexpression of catalase rescues cardiac contractile dysfunction induced by insulin resistance: role of oxidative stress, protein carbonyl formation and insulin sensitivity. Diabetologia 49, 1421-1433

46 McDonald, K. S. (2011) The interdependence of $\mathrm{Ca}^{2}+$ activation, sarcomere length, and power output in the heart. Pflügers Arch. 462, 61-67

47 Ginion, A., Auquier, J., Benton, C. R., Mouton, C., Vanoverschelde, J. L., Hue, L., Horman, S., Beauloye, C. and Bertrand, L. (2011) Inhibition of the mTOR/p70S6K pathway is not involved in the insulin-sensitizing effect of AMPK on cardiac glucose uptake. Am. J. Physiol. Heart Circ. Physiol. 301, H469-H477

48 Summers, S. A., Garza, L. A., Zhou, H. and Birnbaum, M. J. (1998) Regulation of insulin-stimulated glucose transporter GLUT4 translocation and Akt kinase activity by ceramide. Mol. Cell. Biol. 18, 5457-5464 
online dato

\section{SUPPLEMENTARY ONLINE DATA}

\section{CD36 inhibition prevents lipid accumulation and contractile dysfunction in rat cardiomyocytes}

Yeliz ANGIN*1,2 ${ }^{\star 1}$ Laura K. M. STEINBUSCH*1, Peter J. SIMONS $\dagger$, Sabrina GREULICH $\ddagger$, Nicole T. H. HOEBERS*, Kim DOUMA*, Marc A. M. J. van ZANDVOORT*, Will A. COUMANS* ${ }^{\star}$, Wino WIJNEN* ${ }^{*}$ Michaela DIAMANT§, D. Margriet OUWENS $\ddagger$, Jan F. C. GLATZ* and Joost J. F. P. LUIKEN*

*CARIM, Maastricht University, Universiteitssingel 50, P.0. Box 616, 6200 MD Maastricht, The Netherlands, † $†$ Bioceros BV, Yalelaan 46, 3584 CM Utrecht, The Netherlands, †German Diabetes Center, Auf'm Hennekamp 65, 40225 Düsseldorf, Germany, and §̧Diabetes Center, VUmc, Postbus 7057, 1007 MB Amsterdam, The Netherlands

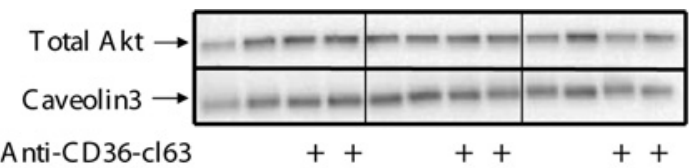

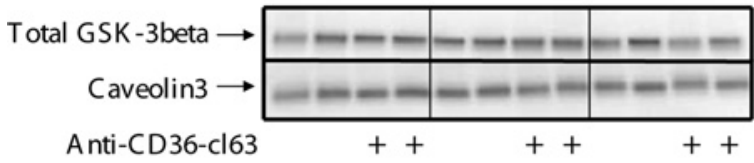

Akt
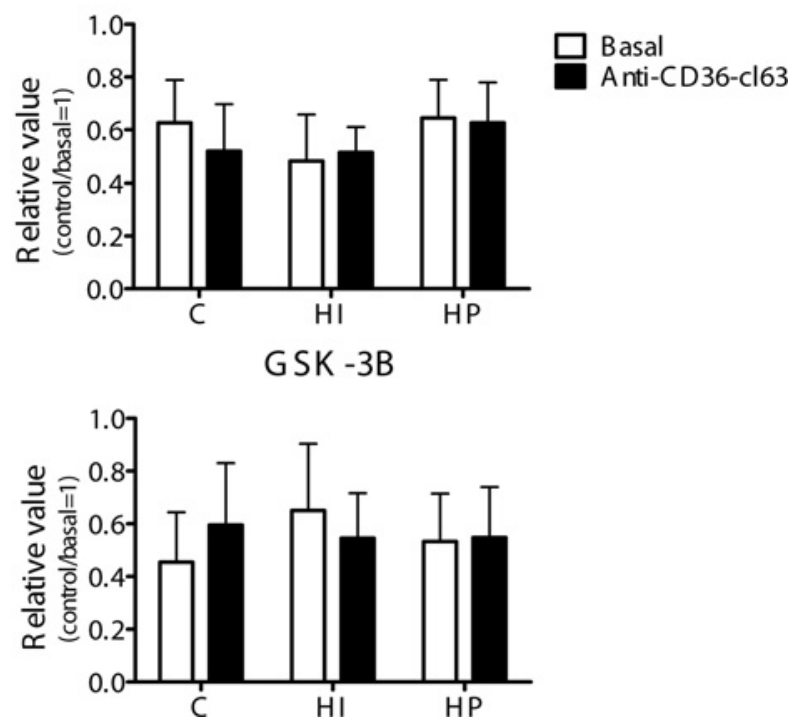

Figure S1 Total expression of Akt and downstream targets in cardiomyocytes is not altered upon $\mathrm{HI}$ and HP treatment in the absence or presence of anti-CD36-cl63

Cardiomyocytes were cultured in control, $\mathrm{HI}$ or $\mathrm{HP}$ medium in the absence or presence of $0.83 \mu \mathrm{g} / \mathrm{ml}$ anti-CD36-cl63. Upon 2 days culturing, cells were allowed to recover for $30 \mathrm{~min}$ prior to short-term (15 min) insulin (100 nM) addition and subsequent Western blot analysis of total Akt and GSK3 $\beta$ content. Hence, the changes in the phosphorylation states of these proteins (see Figure 5 of the main text) are not due to changes in total protein expression.

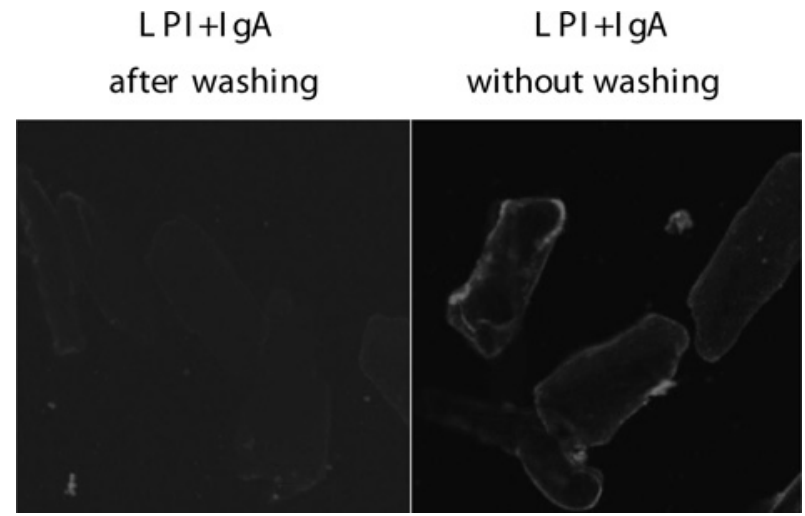

Figure S2 Washing steps after $48 \mathrm{~h}$ culturing almost entirely remove antiCD36-cl63 used to detect the cell surface localization of CD36

Cardiomyocytes were cultured in control medium for $48 \mathrm{~h}$ in the presence of $0.83 \mu \mathrm{g} / \mathrm{ml}$ anti-CD36-cl63 (right-hand panel) and subsequently washed as described in the Materials and methods section of the main text (left-hand panel), and then used for microscopic detection of anti-CD36-cl63 using a FITC-labelled secondary antibody $(n=3)$. It is of note that, upon washing, the fluorescent signal has almost completely disappeared, indicating that the washing procedure effectively removes anti-CD36-cl63.

1 These authors contributed equally to this work.

2 To whom correspondence should be addressed (email y.angin@maastrichtuniversity.nl). 
A

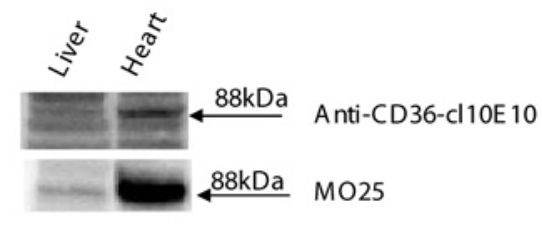

B

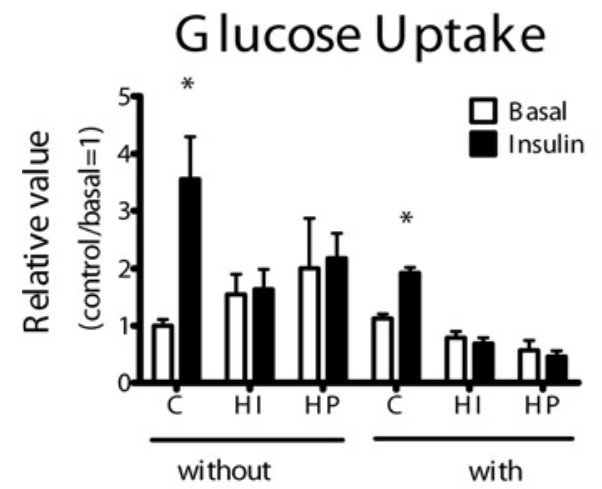

Anti-CD36-Cl10E 10 Anti-CD36-Cl10E 10
C Sarcomere Dynamics
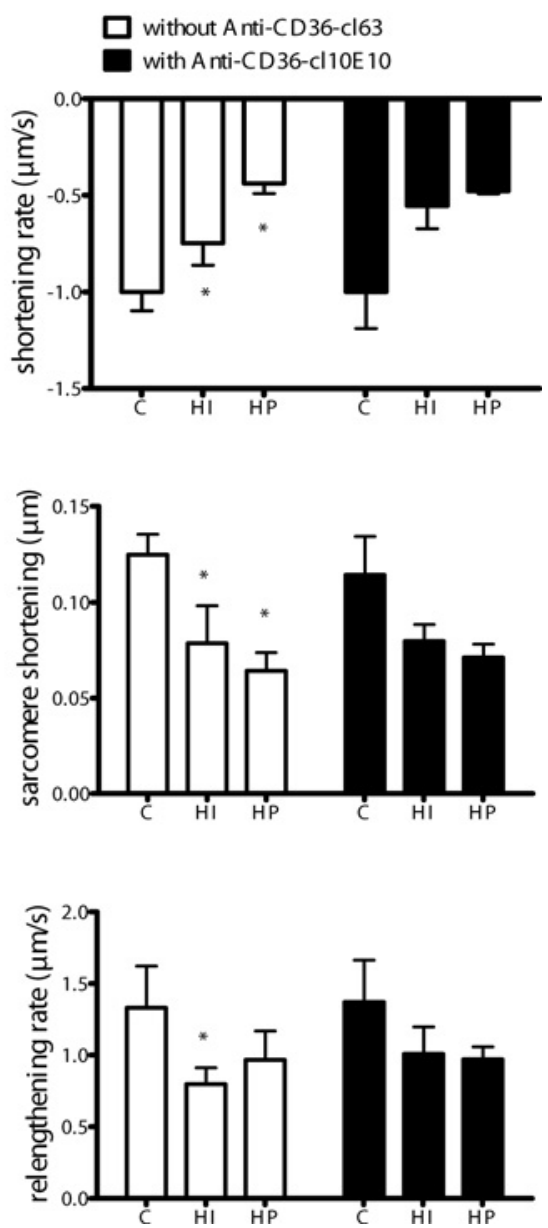

Figure S3 Binding to CD36 is not sufficient for anti-CD36 antibodies to prevent the maladaptive changes in cardiomyocytes upon exposure to lipotoxic conditions

(A) Anti-CD36-C110E10 detects CD36 on Western blots. CD36 protein expression was checked in the homogenates from liver (negative control) and heart tissue by Western blotting. The ability of the anti-CD36-cl10E10 mAb to detect CD36 was compared with the anti-CD36 mAb M025 routinely used for Western blotting. Cardiomyocytes were cultured in control, HI or HP medium in the absence (Basal) or presence of $1.7 \mu \mathrm{g} / \mathrm{ml}$ anti-CD36-cl10E10. (B) Upon 2 days culturing, cells were allowed to recover for 30 min prior to short-term (15 min) insulin (100 nM) addition and subsequent measurement of $\left[{ }^{3} \mathrm{H}\right] \mathrm{glucose}$ uptake. (C) Upon 2 days culturing, cardiomyocytes were used for analysis of peak sarcomere shortening. Values are means \pm S.E.M. $(n=3)$. ${ }^{*} P<0.05$, insulin effect; $\# P<0.05$, medium effect; $\wedge P<0.05$, anti-CD36 effect. These data demonstrate that, in contrast with anti-CD36-cl63 (see Figures 4 and 7 of the main text), anti-CD36-cl10E10 does not induce the substrate switch to increased glucose uptake, and does not preserve contractile function in cardiomyocytes exposed to lipotoxic conditions. In conclusion, merely binding to CD36 is not sufficient for anti-CD36 antibodies to prevent or protect against lipid-induced contractile dysfunction. 


\section{Glucose Uptake}

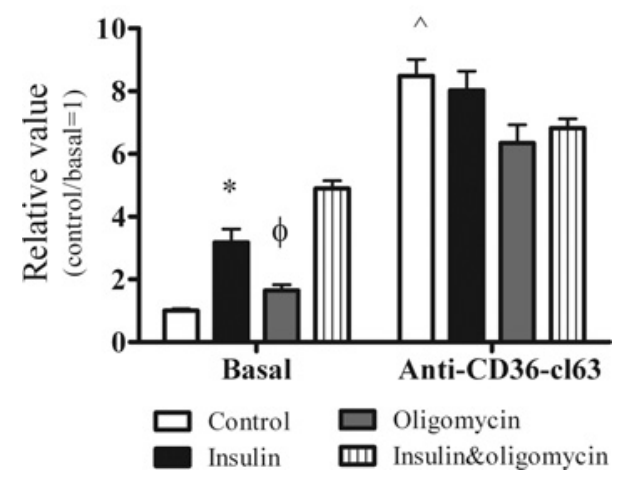

Figure S4 AMPK stimulation does not increase glucose uptake in antiCD36-cl63-treated cardiomyocytes

Cardiomyocytes were cultured in control medium in the absence or presence of $1.7 \mu \mathrm{g} / \mathrm{ml}$ anti-CD36-cl10E10. Upon 2 days culturing, cells were allowed to recover for 30 min prior to short-term (15 min) addition of insulin (100 nM) and/or the potent AMPK stimulator oligomycin $(5 \mu \mathrm{M})$, and subsequent measurement of $\left[{ }^{3} \mathrm{H}\right] \mathrm{glucose}$ uptake. Values are means \pm S.E.M. $(n=3)$. ${ }^{\star} P<0.05$, insulin effect; $\phi P<0.05$, oligomycin effect; $\wedge P<0.05$, anti-CD36 effect. These data demonstrate that short-term AMPK stimulation of anti-CD36-cl63-treated cardiomyocytes, in contrast with basally cultured cardiomyocytes, either in the absence or presence of short-term insulin stimulation, does not stimulate glucose uptake. We suggest that anti-CD36-cl63-treatment leads to a maximal depletion of GLUT4 from the intracellular storage compartment, so that additional treatment of cardiomyocytes with GLUT4 translocation-inducing stimuli will be futile.

Received 9 January 2012/14 June 2012; accepted 10 July 2012

Published as BJ Immediate Publication 10 July 2012, doi:10.1042/BJ20120060 